\title{
The Impact of the Outcome of Treating a High Anal Fistula by Using a Cutting Seton and Staged Fistulotomy on Saudi Arabian Patients
}

\author{
Bader Hamza Shirah ${ }^{1}$, Hamza Asaad Shirah ${ }^{2}$ \\ ${ }^{1}$ King Abdullah International Medical Research Center, King Saud bin Abdulaziz University for Health Sciences, Jeddah; ${ }^{2}$ Department of \\ General Surgery, Al Ansar General Hospital, Medina, Saudi Arabia
}

Purpose: A cutting seton is used after a partial distal fistulotomy to treat patients with a high exrasphincteric fistula in ano to avoid fecal incontinence and recurrence. In Saudi Arabia, religious practices necessitate complete cleanness, which makes conditions affecting anal continence a major concern to patients affected by an anal fistula. Therefore, we aimed to evaluate the efficiency of the cutting seton in treating a high anal fistula among Saudi Arabians.

Methods: Between January 2005 and December 2014, a prospective study was done for 372 Saudi Arabian patients diagnosed as having a high anal fistula and treated with a cutting seton at Al-Ansar General Hospital, Medina, Saudi Arabia. 0 -silk sutures were used. All patients underwent the same preoperative assessment, operative technique, and postoperative follow-up. Weekly, the seton was tightened in outpatient clinics.

Results: Two hundred ninety-eight patients $(80.1 \%)$ were males and $74(19.9 \%)$ females. The duration of symptoms varied from 3-21 months. The fistula healed completely in 363 patients (97.6\%); 58 patients (15.6\%) reported some degree of incontinence to flatus, but none to feces. In 9 patients $(2.4 \%)$ the fistula recurred.

Conclusion: The utilization of the cutting seton method in the treatment of patients with a high anal fistula is highly efficient as it simultaneously drains the abscess, cuts the fistulous tract, and causes fibrosis along the tract. Treatment of a high anal fistula by using a staged fistulotomy with a cutting seton was very rewarding to Saudi Arabian patients who feared anal incontinence for religious reasons and was associated with low postoperative complication and recurrence rates.

Keywords: High anal fistula; Staged fistulotomy; Cutting seton; Saudi Arabia

\section{INTRODUCTION}

A fistula in ano is a very common perianal condition associated with considerable morbidity and inconvenience to the patient. It is described as a hollow tract lined with granulation tissue that connects an in-depth primary opening inside the anal canal to a

Received: March 28, 2017 - Accepted: March 23, 2018

Correspondence to: Bader Hamza Shirah, M.S.

King Abdullah International Medical Research Center, King Saud bin Abdulaziz University for Health Sciences, P.0. Box: 65362, Jeddah 21556, Saudi Arabia

Tel: +966-506201963, E-mail: shirah007@ksau-hs.edu.sa ORCID code: https://orcid.org/0000-0001-6493-2155

(C) 2018 The Korean Society of Coloproctology

This is an open-access article distributed under the terms of the Creative Commons Attribution NonCommercial License (http://creativecommons.org/licenses/by-nc/4.0) which permits unrestricted noncommercial use, distribution, and reproduction in any medium, provided the original work is properly cited. superficial secondary opening in the perianal skin. It is mostly nonspecific (idiopathic, cryptoglandular) with infection of an anal gland in the intersphincteric space as the initiating pathology [1]. However, it could be associated with several specific conditions, such as Crohn disease [2,3], tuberculosis [4], malignancy [5], lymphogranuloma venereum [6], presacral dermoid cysts [7], rectal duplication [8], actinomycosis infection [9], perianal trauma, and foreign bodies [10]. It is a chronic manifestation of an acute perirectal process that forms an anal abscess [11]. When the abscess ruptures or is surgically drained, an epithelialized track may form to connect the abscess in the anus or rectum with the superficial perirectal skin [12]. The incidence of an anal fistula developing as a consequence of an anal abscess ranges from $26 \%$ to $38 \%$ [13]. The mean age at presentation is 40 years (range, 20-60 years) [14]. Males are twice as likely to develop a fistula in ano than females [12]. Milligan and Morgan [15] classified a fistula in ano as either anal 
or anorectal in relation to the anorectal ring in maintaining continence and further subdivided each into low and high. In the low fistula, the internal orifice of the fistula begins below the puborectalis, and the track usually passes through few or no sphincter muscle fibers and is relatively close to the skin. On the other hand, in the high fistula, the internal orifice begins above the puborectalis, and a track usually passes through or above a good number of muscle fibers; its route could be more complicated and further away from the skin.

Park's classification, which is widely used and accepted today [16], divides a fistula based on the relationship between the tract and the anal sphincters into 4 groups: intersphincteric, extrasphincteric, transsphincter, and suprasphincteric. The 4 general types of anorectal fistulae can be described as follows: The intersphincteric fistula begins at the dentate line, ends at the anal verge, tracks along the intersphincteric plane between the internal and the external anal sphincters, and terminates in the perianal skin. The extrasphincteric fistula is mostly in a high position in the anal canal and is located proximal to the dentate line. It envelops the whole sphincter apparatus, which includes the levators, and terminates in the skin overlying the buttock. The transsphincteric fistula tracks through the external sphincter into the ischiorectal fossa, envelopes parts of the internal and the external sphincters, and often terminates in the skin overlying the buttock. The suprasphincteric fistula usually originates at the anal crypt, encircles the entire sphincter apparatus, and terminates in the ischiorectal fossa. All these types of fistulas may be associated with an adjacent communicating blind track.

The division into simple and complex fistulae entails the risk of sphincter dysfunction after treatment. However, the identification of the tracts in high/complex fistulae requires a combination of careful clinical, and perhaps radiological, assessment before the intervention. Hydrogen peroxide was reported to enhance endorectal ultrasound and magnetic resonance imaging (MRI) and may aid in delineating the tracts [17]. The diagnosis is primarily based on characteristic findings, such as a perirectal skin lesion, pain, and purulent drainage, in the patient's medical history and on physical examination. The patients usually provide a reliable history of previous pain, swelling, and spontaneous or planned surgical drainage of the anorectal abscess while perineal and digital rectal examinations will allow the anal sphincter anatomy and tone to be assessed before surgery [18].

The main principles of anal fistula surgery are to eliminate the fistula (tract), prevent recurrence, and preserve the anal sphincter function. Setons have been used to manage anal fistulae for hundreds of years. The term seton was derived from the Latin word seta which means a bristle. Setons are commonly used for high or complex fistulae to avoid fecal incontinence and recurrence [19]. A cutting seton is preferred when the entire sphincter is not involved, and a drainage seton is considered if the tract passes deep throughout the anal sphincter muscles. The function of the seton is to provide abscess drainage, induce chronic fibrosis, and cut the fistulous tract while preserving the sphincter function. A cutting seton is used after a partial distal fistulotomy to treat patients with a high extrasphincteric fistula in a successful manner with a lower risk of recurrence or incontinence problems [20-22].

The selection of a seton type and method depends on the surgeons' personal preference. A variety of materials have been used which include sutures, stainless-steel wires, depezzar catheters, medicated ksharsootra, self-locking cables, silicone, thread, and rubber bands [23, 24]. Hanley [25] reported the use of a rubberband seton, with good functional results, in the surgical treatment of anterior abscesses related to anal fistulae and anterolateral fistulae in women. Mentes et al. [26] and Chuang-Wei et al. [27] described the use of an elastic seton that was created by cutting a thin (about 2-3 mm), circular strip of a surgical glove, including its thicker sleeve. Culp [28] described the use of a thin Penrose drain (1/4-5/8 in) as a primary operative seton to utilize its elastic properties. Also, a traction technique was applied by using a tie of silk sutured with a noncutting needle through an elastic drain to prevent slippage. Parks and Stitz [29] described the use of a braided nylon suture as a seton for treating complex fistulae. Armstrong et al. [30] described the utilization of a hollow, 3-mm diameter, silastic tube seton that allowed clear visualization of the drained fistula tracks with MRI in the setting of ongoing perianal sepsis.

A fistula in ano is a common entity encountered in our local practice, with an average presentation of 250 patients per year in the outpatient clinic, in addition to 100 patients who visit the emergency department annually. In Saudi Arabia, the Islamic religious practice of daily prayers 5 times a day and at night, which necessitates complete cleanness and is preceded by ablution (the Islamic procedure for washing certain parts of the human body with clean water in preparation for formal prayers), causes great concern among patients suffering from anorectal and urology diseases. The public perception that surgical management of fistula in ano results in a dirty bleeding wound and has an effect on the control of anal continence even for flatulence makes the surgical option a nightmare to most patients. Therefore, any effective method to treat anorectal diseases in general, and fistulae in ano in particular, that provides a clean and dry anus and preserves complete anal control at all the time would have significant meaning to that group of patients. As a consequence of this perception, we have experienced refusal of surgical treatment by many patients and increased use of traditional herbal methods that are popular in the local community, which necessitated the need for an effective treatment protocol for that group of patients. Therefore, we aimed to evaluate the effectiveness of a cutting seton in the treatment of high anal fistulae among Saudi Arabians who fear the surgical option for specific religious reasons.

\section{METHODS}

A prospective cohort study of the surgical treatment outcomes of 372 Saudi Arabian patients, who had been diagnosed to have had 


\section{Coloproctology Bader Hamza Shirah and Hamza Asaad Shirah}

a high anal fistula and who had been treated with a cutting seton at Al-Ansar Public Health General Hospital, Medina, Saudi Arabia, between January 2005 and December 2014 was done. The study protocol was designed on a digital database file in the outpatient department as part of the Quality Care Program at AlAnsar Hospital. The medical data in the digital database were reviewed and analyzed for preoperative factors such as age, sex, duration of the disease. Postoperative factors evaluated were duration until complete cutting through of the seton, complications,

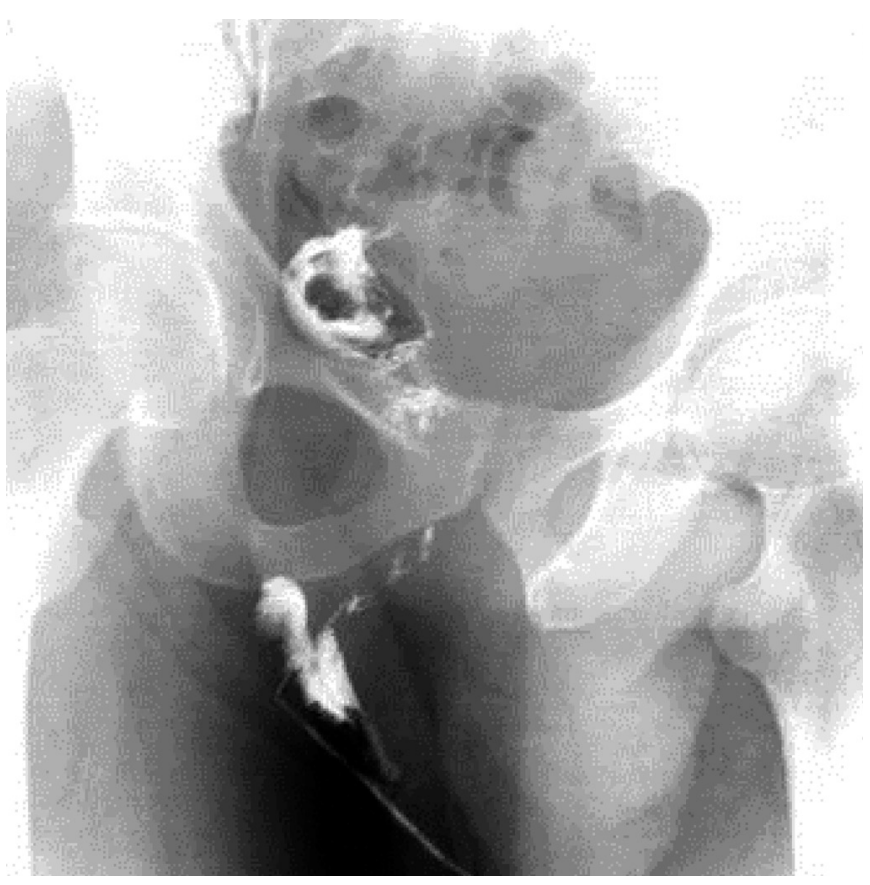

Fig. 1. A fistulogram of a 37-year-old male showing a high posterior anal fistula. incontinence, and recurrence. The patients were referred from local hospitals and primary care centers. Ethical approval was granted by the Ethical Committee of Al-Ansar Hospital and by the Management Guidelines and Clinical Pathway Subcommittee of the Quality Care Program at the same hospital. Informed consent was obtained from all patients prior to participation in the study.

All the patients were referred to the general surgery outpatient clinic; no patient from the Emergency Department was included. The preoperative workup, selection of patients, surgical procedures, and follow-up were done by the same surgical team. All patients had the same preoperative workup (complete blood count, coagulation profile, blood chemistry, chest X-ray, and electrocardiogram). Digital rectal examinations, proctoscopy, fistulography, and MRI were performed in all cases to evaluate the extent of the fistula (Figs. 1, 2). Inclusion criteria included all adult patients above 12 years old according to the age guidelines of the Saudi Arabian Ministry of Health, who had been diagnosed to have a high anal fistula. Thus, all patients who had a low fistula were excluded. The procedure and the postoperative care, including assessment of the degree of incontinence, were carefully explained to the patients. All patients were admitted to the surgical floor one day before surgery and were discharged on the second postoperative day.

Patients were prepared with laxatives and rectal enemas 24 hours before surgery. No antibiotics were used in any patient at any stage during the treatment. The procedure was carried out under general anesthesia, in the lithotomy position; hydrogen peroxide was injected through the external, superficial opening to delineate the tract and help localize the deep internal opening. A grooved surgical probe was introduced through the external opening, and the fistula tract was laid open to the dentate line (from the cutaneous plane to the external sphincter muscle plane). Curettage was performed to the lining of the tract. A 0 -silk suture was tied to the tip

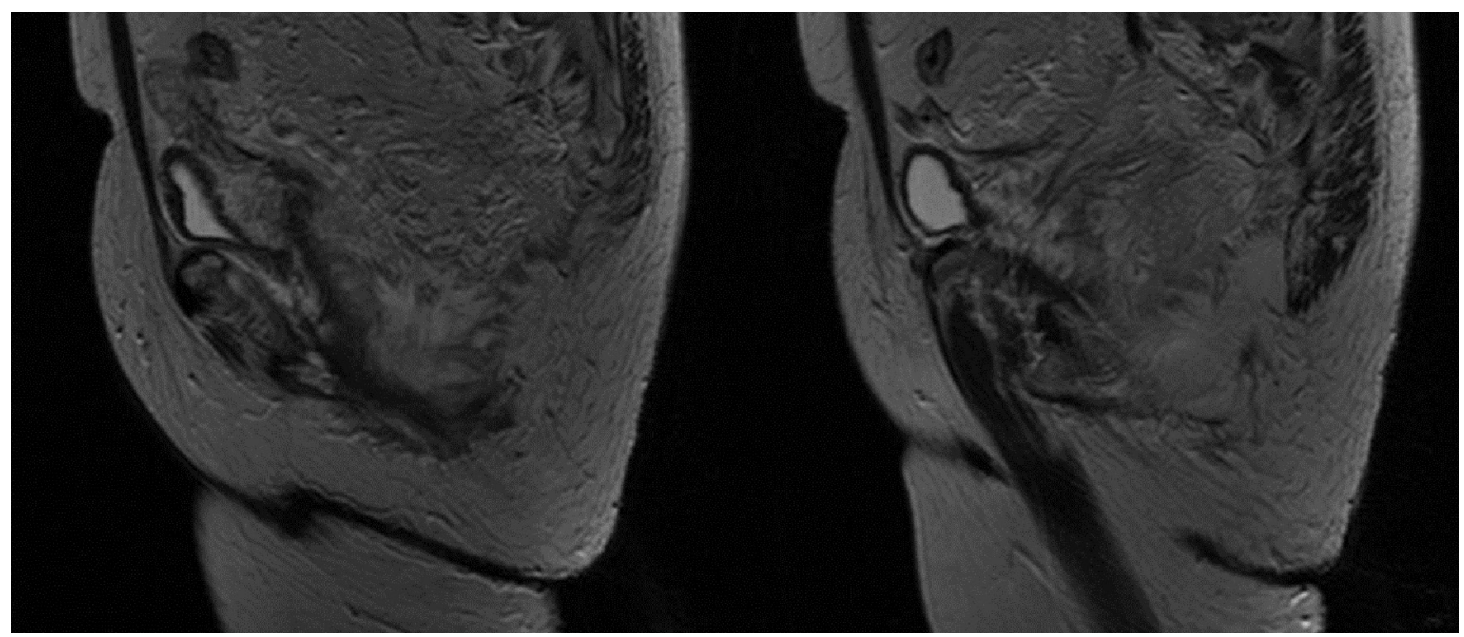

Fig. 2. Magnetic resonance imaging results for a 39-year-old male showing a transsphincteric anal fistula. 
of the probe, passed through the remaining part of the tract, around the external sphincter muscle, brought out via the internal opening and anus, without a sphincterotomy, and delivered outside the anal opening. Both ends of the suture were tightened, and the knot was placed at the muscle side close to the anal opening. Consequently, a suitable length of the suture was left hanging outside the anus for future retightening.

All the patients were discharged on the second postoperative day and given once weekly follow-up appointments for tightening of the seton. The principle of seton treatment depends on a gradual cutting through the muscle, layer after layer, which gives a chance for muscle layer healing while cutting through the next layer. Therefore, the patients were followed-up every week postoperatively until complete cutting through of the seton and healing of the wound, after which the follow-ups were once every month for 6 months to check for the development of any complications such as recurrence or incontinence. All patients were then followed-up every 3 months for 2 years. All patients completed the 2-year follow-up periods. No dropouts were recorded.

We used the Park's incontinence score [31] to assess incontinence postoperatively. That score has four categories: category 1 , patients continent for solid and liquid stool and for flatus; category 2, patients continent for solid and liquid stool, but incontinent for flatus (with or without urgency); category 3, patients continent for solid stool, but incontinent for liquid stool or flatus; category 4 , patients incontinent to formed stool (complete incontinence).

The digital database medical data were reviewed and analyzed for preoperative factors such as age, sex, duration of the disease.

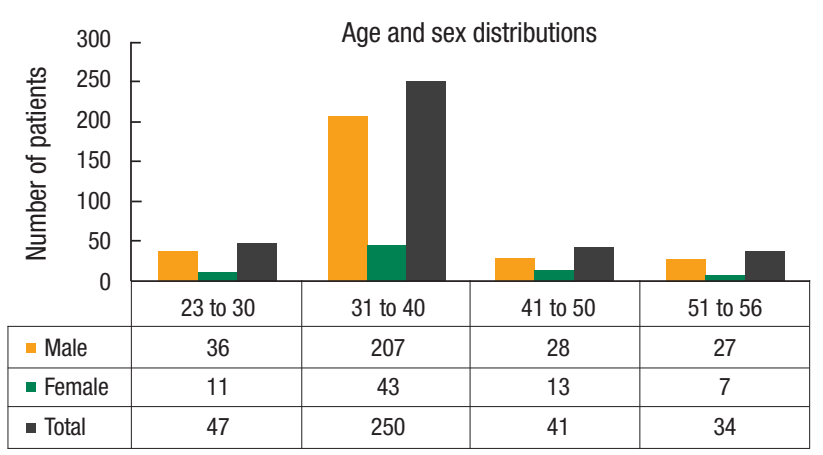

Fig. 3. Age and sex distributions of patients with a high anal fistula.
Postoperative factors evaluated were duration until complete cutting through of the seton, complications, incontinence, and recurrence. IBM SPSS Statistics ver. 22.0 (IBM Co., Armonk, NY, USA) was used for data analysis. Results were represented by percentages and mean. The variables with a $\mathrm{P}$-value where $\mathrm{P} \leq 0.1$ were considered to represent a significant difference statistically.

\section{RESULTS}

Three hundred seventy-two Saudi Arabian patients proven to have had a high anal fistula were included; 298 (80.1\%) were male and $74(19.9 \%)$ female patients, with a male-to-female ratio of $4: 1$. The mean age of the patients was 39.5 years (range, 23-56 years). The mean duration of symptoms was 12 months (range, 3-21 months). The chief complaints were perianal discharge, perianal swelling, pain, skin excoriation, and recurrent fever (Figs. 3, 4).

Two hundred sixty-two patients (70.4\%) had a history of a perianal abscess with drainage. Forty-nine (13.2\%) had a history of a small infected perianal nodule which was opened by the patients themselves, and 41 patients (11\%) had a history of a small infected perianal nodule treated by using traditional herbal medicines. Thirteen patients (3.5\%) were known to have chronic Crohn disease, and 7 patients (1.9\%) had a history of penetrating perianal trauma. A history of previous perianal abscess with drainage was statistically found to be associated with the development of an anal fistula $(\mathrm{P}<0.05)$ (Table 1). Comorbid diseases were as follows: 28 patients (7.5\%) were diabetics, 23 (6.2\%) had hypertension, 17 (4.6\%) had gallstone diseases, 13 (3.5\%) were known to have chronic

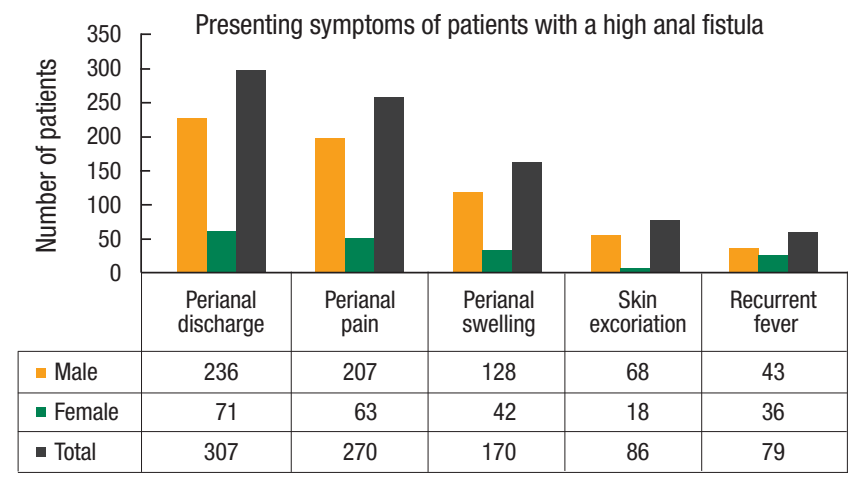

Fig. 4. Presenting symptoms of patients with a high anal fistula.

Table 1. Predisposing conditions in patients with a high anal fistula

\begin{tabular}{lccc}
\hline Predisposing factor & Male & Female & Total, $\mathrm{n}(\%)$ \\
\hline Perianal abscess with drainage & 191 & 71 & $262(70.4)$ \\
Perianal small infected nodule opened by the patients themselves & 35 & 14 & $49(13.2)$ \\
Perianal small infected nodule treated by herbals & 22 & 19 & $41(11)$ \\
Chronic cases of Crohn disease & 11 & 2 & $13(3.5)$ \\
Perianal penetrating trauma & 7 & 0 & $7(1.9)$ \\
\hline
\end{tabular}


Table 2. Postoperative complications in patients with a high anal fistula who had been treated by using a partial fistulotomy and seton

\begin{tabular}{lrcc}
\hline Postoperative complication & Male & Female & Total, $\mathbf{n}(\%)$ \\
\hline Perianal soiling & 153 & 23 & $176(47.3)$ \\
Pain & 131 & 63 & $194(52.2)$ \\
Transient incontinence for flatus & 37 & 21 & $58(15.6)$ \\
Recurrence & 8 & 1 & $9(2.4)$ \\
\hline
\end{tabular}

Crohn disease, 5 (1.3\%) had ischemic heart disease, and 3 (0.8\%) had hypothyroidism.

Intraoperative reports documented the posterior fistula tract according to Goodsall's rule in all 372 patients (100\%). A posterior location of the fistula was statistically found to be associated with good outcome $(\mathrm{P}<0.05)$. Also, an extrasphincteric fistula was documented in 132 patients (35.5\%), a transsphincteric fistula in 127 patients (34.1\%), and a suprasphincteric fistula in 113 patients (30.4\%).

Regarding postoperative complications, 176 patients (47.3\%) complained of perianal soiling during the initial postoperative days, which was treated by using a Sitz bath 3 times daily; 194 patients $(52.2 \%)$ experienced pain due to the tightness of the seton, which was relieved by using oral analgesics; and 58 patients (15.6\%) complained of transient incontinence for flatus, which disappeared in 2 weeks in all patients. No fecal incontinence was recorded in any patient. The seton gradually cut through the fistula tract in all patients; no failure was recorded regarding the seton. The mean duration of complete cutting was 8 weeks (range, 5-11 weeks). The mean duration of complete wound closure was 9 weeks (range, 6-12 weeks) (Table 2, Fig. 5).

The recurrence rate was (2.4\%), with 9 patients experiencing a recurrence of the fistula in ano. Among them, $4(1.1 \%)$ were diabetics, and $5(1.3 \%)$ had Crohn disease. They were all retreated by using the same method, with subsequent healing in all. The cutting seton technique was found statistically to be associated with good outcome $(\mathrm{P}<0.05)$.

Overall, all patients included in the study felt comfortable and were satisfied with this treatment. In the end, none of them complained of permanent flatus, fecal incontinence, or disturbance of cleanness, especially after ablution and during prayers. All $372 \mathrm{pa}-$ tients had a Park's incontinence score of 1 postoperatively.

\section{DISCUSSION}

Anal fistulae are reported worldwide to occur most commonly during the third and the fourth decades of life. The age distribution (mean, 39.5 years) and male predominance (80.1\%) seen in our study are in accordance with those seen in other international studies [32]. A fistulectomy has been reported by many clinical studies as a sufficient surgical technique for successful management of a simple or a low transsphincteric anal fistula. When an
Duration of complete cutting through of seton and wound healing - Complete cutting through of seton - Wound healing

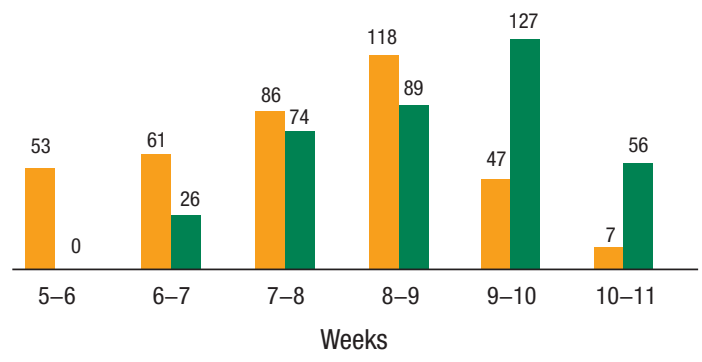

Fig. 5. Duration of complete cutting through of seton and wound healing.

advanced complicated transsphincteric or suprasphincteric fistula is encountered, many operative options, including the utilization of advancement flaps, application of an anal plug, the use of fibrin glue, radiofrequency ablation, intersphincteric fistula tract ligation, or application of a loose seton, may be involved [33].

Usually, the healing after the seton technique is uneventful, though minor control problems may happen in a variable number of patients. A study done at King Faisal Specialist Hospital in Riyadh, Saudi Arabia, by Isbister and Al Sanea [21] reported that the rate of flatus incontinence after surgery was $36 \%$ and that of semiformed fecal incontinence was $8.5 \%$ while that of formed fecal incontinence was $2.3 \%$. In our study, 58 patients (15.6\%) complained of transient incontinence for flatus, which disappeared in 2 weeks in all patients. No fecal incontinence was recorded in any patient, a finding that correlates with the results of many other international studies $[1,6,10]$.

The mean healing time ( 9 weeks) and the seton cutting through time ( 8 weeks) in our study were in accordance with those reported in other international studies [17-22]. In our study, we observed that the etiology of a single fistula tract combined with a posterior position of the fistula tract were major factors that contributed significantly to the high success rate we achieved. Another observation is that leaving the external orifice of the sinus open, which functionally contributed to spontaneous drainage and simultaneous closure of the internal and the external orifices, helped to improve the process of wound healing and consequently contributed to the prevention of recurrence by helping to vitalize the tissues around the external orifice that were poorly perfused.

The worldwide incontinence rate following anal fistula surgical treatment using different kinds of medical materials for the seton is reported to range from $0 \%$ to $62 \%$ [6]. In addition, the recurrence rate varies from $0 \%$ to $16 \%$ [1]. The results of our study showed that no permanent incontinence was recorded in any patient $(0 \%)$ while the recurrence rate was (2.4\%). An analysis of the international reports in the literature shows that a wide range of incontinence rates is reported after cutting seton treatment, and Ritchie et al. [6] found no relationship between incontinence and the fre- 
quency of tightening, the type of seton, or the classification of the fistula itself. The factors associated with fistula recurrence may include the complexity and the level of the fistula, the absence or presence of a horseshoe extension, the distance of laterality of the external opening, technical failure by the surgeon in identifying the internal opening during the initial surgery, and the overall surgical experience of the operating surgeon in complicated proctologic practice [34].

The disease of perianal fistula and its complications can have significant implications for the quality of life of the patient because the sequelae range from minor pain, bad hygiene, social embarrassment, to frank sepsis [35]. We noticed a considerable satisfaction among our Saudi Arabian patients regarding the high rate of complete healing and the avoidance of incontinence following treatment with a seton. This satisfaction was due not only to the avoidance of hygienic social embarrassment but also to the very significant positive impact on religious practices (ablution, prayer, attendance at Mosques, performances of Umrah and Hajj, and fasting).

In conclusion, the options for treating an anal fistula still remain a surgical problem. The utilization of the cutting seton method in the treatment of a patient with a high anal fistula is highly efficient as it simultaneously drains the abscess, cuts the fistulous tract, and causes fibrosis along the tract. Furthermore, it is simple and safe, and the patient's tolerance for the stages of the procedure is good while the risks of incontinence and recurrence are not remarkable. The use of this method was very rewarding to Saudi Arabian patients who feared anal incontinence for particular religious reasons.

\section{CONFLICT OF INTEREST}

Both authors declare no conflicts of interest.

\section{REFERENCES}

1. Vial M, Parés D, Pera M, Grande L. Faecal incontinence after seton treatment for anal fistulae with and without surgical division of internal anal sphincter: a systematic review. Colorectal Dis 2010; 12:172-8.

2. Rizzo JA, Naig AL, Johnson EK. Anorectal abscess and fistula-inano: evidence-based management. Surg Clin North Am 2010;90:4568.

3. Soltani A, Kaiser AM. Endorectal advancement flap for cryptoglandular or Crohn's fistula-in-ano. Dis Colon Rectum 2010;53: 486-95.

4. Shukla HS, Gupta SC, Singh G, Singh PA. Tubercular fistula in ano. Br J Surg 1988;75:38-9.

5. Nelson RL, Prasad ML, Abcarian H. Anal carcinoma presenting as a perirectal abscess or fistula. Arch Surg 1985;120:632-5.

6. Ritchie RD, Sackier JM, Hodde JP. Incontinence rates after cutting seton treatment for anal fistula. Colorectal Dis 2009;11:564-
71.

7. Pye G, Blundell JW. Sacrococcygeal teratoma masquerading as fistula-in-ano. J R Soc Med 1987;80:251-2.

8. Narasimharao KL, Patel RV, Malik AK, Mitra SK. Chronic perianal fistula: beware of rectal duplication. Postgrad Med J 1987;63: 213-4.

9. Harris GJ, Metcalf AM. Primary perianal actinomycosis. Report of a case and review of the literature. Dis Colon Rectum 1988;31: 311-2.

10. Buchanan GN, Williams AB, Bartram CI, Halligan S, Nicholls RJ, Cohen CR. Potential clinical implications of direction of a transsphincteric anal fistula track. Br J Surg 2003;90:1250-5.

11. Abcarian H. Anorectal infection: abscess-fistula. Clin Colon Rectal Surg 2011;24:14-21.

12. Whiteford MH, Kilkenny J 3rd, Hyman N, Buie WD, Cohen J, Orsay C, et al. Practice parameters for the treatment of perianal abscess and fistula-in-ano (revised). Dis Colon Rectum 2005;48: 1337-42.

13. Ramanujam PS, Prasad ML, Abcarian H, Tan AB. Perianal abscesses and fistulas. A study of 1023 patients. Dis Colon Rectum 1984; 27:593-7.

14. Niyogi A, Agarwal T, Broadhurst J, Abel RM. Management of perianal abscess and fistula-in-ano in children. Eur J Pediatr Surg 2010; 20:35-9.

15. Milligan ET, Morgan CN. Surgical anatomy of the anal canal with special reference to anorectal fistulae. Lancet 1934;2:1150-6.

16. Parks AG, Gordon PH, Hardcastle JD. A classification of fistulain-ano. Br J Surg 1976;63:1-12.

17. García-Aguilar J, Belmonte C, Wong DW, Goldberg SM, Madoff $\mathrm{RD}$. Cutting seton versus two-stage seton fistulotomy in the surgical management of high anal fistula. Br J Surg 1998;85:243-5.

18. Malik AI, Nelson RL. Surgical management of anal fistulae: a systematic review. Colorectal Dis 2008;10:420-30.

19. Theerapol A, So BY, Ngoi SS. Routine use of setons for the treatment of anal fistulae. Singapore Med J 2002;43:305-7.

20. Hämäläinen KP, Sainio AP. Cutting seton for anal fistulas: high risk of minor control defects. Dis Colon Rectum 1997;40:1443-6.

21. Isbister WH, Al Sanea N. The cutting seton: an experience at King Faisal Specialist Hospital. Dis Colon Rectum 2001;44:722-7.

22. Tyler KM, Aarons CB, Sentovich SM. Successful sphincter-sparing surgery for all anal fistulas. Dis Colon Rectum 2007;50:1535-9.

23. Awad ML, Sell HW, Stahlfeld KR. Split-shot sinker facilitates seton treatment of anal fistulae. Colorectal Dis 2009;11:524-6.

24. Takesue Y, Ohge H, Yokoyama T, Murakami Y, Imamura Y, Sueda T. Long-term results of seton drainage on complex anal fistulae in patients with Crohn's disease. J Gastroenterol 2002;37:912-5.

25. Hanley PH. Rubber band seton in the management of abscess-anal fistula. Ann Surg 1978;187:435-7.

26. Mentes BB, Oktemer S, Tezcaner T, Azili C, Leventoğlu S, Oğuz M. Elastic one-stage cutting seton for the treatment of high anal fistulas: preliminary results. Tech Coloproctol 2004;8:159-62.

27. Chuang-Wei C, Chang-Chieh W, Cheng-Wen H, Tsai-Yu L, Chun- 


\section{Coloproctology Bader Hamza Shirah and Hamza Asaad Shirah}

Che F, Shu-Wen J. Cutting seton for complex anal fistulas. Surgeon 2008;6:185-8.

28. Culp CE. Use of Penrose drains to treat certain anal fistulas: a primary operative seton. Mayo Clin Proc 1984;59:613-7.

29. Parks AG, Stitz RW. The treatment of high fistula-in-ano. Dis Colon Rectum 1976;19:487-99.

30. Armstrong T, Tarver DS, Clarke AD, Talbot RW, Nash GF. Hollow seton for magnetic resonance imaging fistula visualization. Colorectal Dis 2006;8:615.

31. Browning GG, Parks AG. Postanal repair for neuropathic faecal incontinence: correlation of clinical result and anal canal pressures. Br J Surg 1983;70:101-4.

32. Gurer A, Ozlem N, Gokakin AK, Ozdogan M, Kulacoglu H, Aydin
R. A novel material in seton treatment of fistula-in-ano. Am J Surg 2007;193:794-6.

33. M GP, M GC, S GU, L SN, P ME, R FB, et al. Modified loose-seton technique for the treatment of complex anal fistulas. Colorectal Dis 2010;12(10 Online):e310-3.

34. Zbar AP, Ramesh J, Beer-Gabel M, Salazar R, Pescatori M. Conventional cutting vs. internal anal sphincter-preserving seton for high trans-sphincteric fistula: a prospective randomized manometric and clinical trial. Tech Coloproctol 2003;7:89-94.

35. Williams JG, Farrands PA, Williams AB, Taylor BA, Lunniss PJ, Sagar PM, et al. The treatment of anal fistula: ACPGBI position statement. Colorectal Dis 2007;9 Suppl 4:18-50. 